\title{
NoPlagiat: Helps students to avoid plagiarism and copyright issues
}

Mikael Rosell

\section{Book Chapter}

N.B.: When citing this work, cite the original article.

Part of: ICERI2016 : Proceedings 14th-16th Noivember 2016 : 9th International Conferende of Education, Research and Innovation. Louis Go mez Chova, A Lo' pez Marti' nez and I Candel Torres (Eds) , 2016, pp. 7390-7397. ISBN: 9788461758951

ICERI Proceedings, 2340-1095, No. 2016

DOI: https://doi.org/10.21125/iceri.2016.0681

Copyright: IATED Academy

Available at: Linköping University Institutional Repository (DiVA)

http://urn.kb.se/resolve?urn=urn:nbn:se:liu:diva-139376 


\title{
NOPLAGIAT: HELPS STUDENTS TO AVOID PLAGIARISM AND COPYRIGHT ISSUES
}

\author{
M. Rosell ${ }^{1}$ \\ ${ }^{1}$ Linköping University (SWEDEN)
}

\begin{abstract}
In January 2014, a self-study tutorial for undergraduate students about how to avoid plagiarism and copyright issues was launched at Linköping University, Sweden. The self-study guide was developed by the Library in collaboration with the University's Disciplinary Board Committee.
\end{abstract}

The purpose of NoPlagiat is that undergraduate students at Linköping University can learn on their own more about how to avoid plagiarism and learn more about copyright laws and understand how they may use other people's material.

In this paper we wish to share our experience with the work of designing, promoting and updating the NoPlagiat tutorial. We also want to discuss how our expectations turned out in reality and the feedback we have gotten from our users.

The reason why we started to create a self-study tutorial was a general experience among library staff that they got more and more questions from undergraduate students related to copyright, plagiarism and referencing. Another reason was that plagiarism was the most common reason, 460 cases of a total of 801, why undergraduate students ended-up in the Disciplinary Board at Swedish universities and colleges 2012 [1]. This made it clear that there was a need for major preventive measures for students within the field of plagiarism and copyright.

The tutorial was created with the web development tool Macromedia Dreamweaver. It consists of five modules and at the end of each module the students' knowledge is tested with some exercises. The modules are: What is plagiarism?, Referencing, Quoting, Paraphrasing and Copyright.

Our hope was that it would become mandatory in some courses at the university for undergraduate students foremost during their first year of study. One idea was that the students could do NoPlagiat on their own, for example before a session and during the lesson thereafter teachers and students could then have a deeper discussion regarding the topics in the guide. If all undergraduate students at Linköping University went through the NoPlagiat tutorial they would learn more about what plagiarism is and could thus avoid getting into disciplinary difficulties.

To accomplish this we promoted the NoPlagiat tutorial in different forums at the university during spring 2014. We e.g. presented the tutorial at a library board meeting. One direct effect of this was that the NoPlagiat tutorial became mandatory the same year in an introduction course to university studies at the faculty Science and Engineering/the Institute of Technology. We also sent email to all the program committees and managers on the four faculties of the university were we presented the NoPlagiat tutorial and recommended them to use it in courses in their education programs. A follow-up survey was sent to the program committees and managers during April and May 2015 but had a very low response rate. Unfortunately from the responses we received we learned that the program committees didn't think that the tutorial would fit in in their courses. I'm sorry to say that no respondent mentioned that NoPlagiat was used or discussed during a session. One program invited us to present the selfstudy tutorial on their department meeting. Our conclusion of this survey is that we probably need to promote NoPlagiat even better so it will be used mandatory in not only one but all four faculties of the university.

Keywords: Plagiarism, copyright, referencing, undergraduate students, self-study tutorial 


\section{INTRODUCTION}

It all began with an email from the Deputy Vice-chancellor at Linköping University to the library's Plagiarism and Copyright Issues group in early 2013. The email contained an article that presented a study that showed how a relatively short self-study guide significantly reduces the amount of plagiarism among students [2]. This article started a discussion in the library's Plagiarism and Copyright Issues group that a self-study tutorial would be helpful for our students'.

The result of the discussion became a decision to create Linköping University's own self-study tutorial. Another solution could have been to re-use an already existing guide but it was dismissed since it was found to be too complicated and didn't really fit our needs. A contributing factor for this decision was a general experience that the library received an increasing number of questions at the information desk and via email about plagiarism and copyright. Along with that, plagiarism was the most common reason, 460 cases of a total of 801 , why undergraduate students ended-up before the Disciplinary Boards at Swedish universities and colleges in 2012 [1]. These factors made it clear that there was a need for major preventive measures for students within the field of plagiarism and copyright.

Academic dishonesty, which includes Plagiarism, is present in higher education all over the world [3][6]. The types of plagiarism committed are for example copying text word for word or paraphrasing from a source without a proper reference [4]-[6]. Reasons for students to commit plagiarism varies but includes the small risk of getting caught, the pressure of passing a course and ignorance [5], [6]. There are variations between different studies about who are more likely to plagiarize texts; younger students and international students were two identified groups [4], [7]. Walker [4] however did not find support in his study for the idea that first-year students plagiarized more than others. Some studies mean that the digital age has increased the number of plagiarism cases [5], [7]. How to handle this problem is under debate, some authors mean that there tends to be too much focus within higher education on detection and punishment using automatic plagiarism detection tools like Turnitin rather than on educating students in academic writing and proper academic conduct [8], [9]. Because not all cases of plagiarism are committed intentionally, studies show that undergraduate students in higher education have an inadequate and/or inaccurate comprehension about what is considered plagiarism [5], [10], [11]. Research also points out that preventive measures are important so students do not plagiarize by mistake or simply by ignorance [2].

Initially there were five librarians involved in the project team and all were members of the library's Plagiarism and Copyright Issues group. Later on we also involved members from the university disciplinary board for advice and feedback. An application for funds to develop and maintain a selfstudy guide about plagiarism and copyright was sent by the library's Plagiarism and Copyright Issues group to the Deputy Vice-chancellor in March 2013. The application was granted, which made the project university funded, which is unusual for library projects in Sweden and made it easier for the future project team to devote time to the project.

The purpose of the self-study tutorial, later named NoPlagiat, would be that undergraduate students at Linköping University, on their own, could learn how to avoid plagiarism and learn about copyright laws and understand how they may use other people's material. If all students at Linköping University went through the NoPlagiat tutorial they would learn more about what plagiarism is and could thus avoid getting into disciplinary difficulties. Therefore one target group for our self-study tutorial was first-year undergraduate students since we wanted to reach the students as early as possible when they may not yet had time to learn proper academic conduct.

We also needed to reach international students since the rules of plagiarism can vary significantly between different cultures and there can be difficulty in writing academic texts in English, a second language for many International students [4].

\subsection{Literature review}

We started the project by devoting ourselves to a comprehensive review of both the literature and other self-study tutorials online, Swedish and international. The literature review showed us some important things. For a self-study tutorial to be used by undergraduate students it needs to be incorporated into a course, preferable about academic writing, part of an education program [12]. The incorporation of a self-study tutorial into a course requires a successful collaboration between librarians and teachers [13]. Mages and Garson [14] also emphasize the importance of the library collaborating with teachers and other crucial university staff members. An online self-study tutorial must be of high quality and be 
accessible, it also needs to be evaluated during and after the development phase to determine if the needs of the intended users are met [14]. The best way to evaluate a tutorial, according to Lund and Pors, is to use student groups from different disciplines and study years [15]. An online self-study tutorial must be updated regularly, otherwise it will quickly be outdated and forgotten [14], [15]. We found in our review of online tutorials many that were outdated. Therefore it was important that the Plagiarism and Copyright Issues group was not only responsible for designing and promoting the self-study tutorial but also for maintenance.

By constructing a self-study tutorial that automatically generates the results from a quiz with similar questions both before and after the tutorial, it's possible to assess what the students have learned about plagiarism [12], [13]. The results can also be used in a course grading process [12]. Jackson [13] showed in her study that when it came to grasping the content in a self-study tutorial, the section explaining paraphrasing was the hardest to understand for undergraduate students. As a direct result of this study, teachers at the relevant university introduced lectures about paraphrasing [13].

\section{DESIGN OF THE NOPLAGIAT TUTORIAL}

A self-study tutorial that inspired and impressed us was Stop Plagiarism, the result of a Danish joint project from 2010 between several Danish universities and the Danish electronic research library association [16]. Another one was Refero: an anti-plagiarism Tutorial from 2009, created by the Swedish university libraries of Blekinge Institute of Technology and Linnaeus University [17].

We wanted undergraduate students to be able to use the tutorial on their own in order to learn more about plagiarism and copyright. The focus was to be on how to do something in correctly, in coherence with recommendations from the literature [8], [9]. Therefore, we needed to present how to apply academic conduct in self-written texts in a clear and consistent manner.

Inspired by Stop Plagiarism, Refero and other online self-study tutorials we decided that the tutorial should consist of five modules: what is plagiarism?, Referencing, Quoting, Paraphrasing and Copyright. The guide ends with a short summary. After each module the students' knowledge would be tested with a quiz. An idea we got both from the tutorial in Jackson's study and from the Simon Fraser University (SFU) Library's Plagiarism Tutorial [13], [18].

Inspired by Dee and Jacob [2], our purpose was to make the NoPlagiat tutorial rather short; it should not take more than 15 minutes to complete. After some discussion it was decided that the tutorial would only be text-based due to the fact that it would be easier to develop and maintain since the project team lacked skills in advanced programming. The quiz does not generate a total score that passes or fails users. Here we did not follow the recommendation we saw in the literature [12], [13] and this actually raised questions from teachers later on. The reason for this was that the project team did not want the tutorial to be a test that could be measured but rather a support service to facilitate students own learning.

The project team appointed one and sometimes two persons responsible for each module, the remaining members read and commented their texts. Every module consists of text that explains a specific topic followed by relevant examples. Since international students was one of our target groups we had to construct an English version of the tutorial. This was no problem because one of the group members was a native-English speaker. One challenge was to choose which reference style to use. Since Linköping University uses a wide variety of styles we settled for three commonly known styles Harvard, Vancouver and Oxford that also shows three different ways of displaying in-text citations, author-date, numerical and footnotes. The Harvard style became the dominant one in our reference examples mostly because it exist in many different versions and resembles other styles like APA6 and Chicago, so it would probably be familiar to many students. Because an earlier study pointed out that paraphrasing could be difficult for students to comprehend we tried to focus extra on writing simple and clear examples of correct paraphrasing in our paraphrase module [13].

Each quiz in the end of the modules was designed with multiple choices and correct possible answers. The user cannot proceed to the next question until the correct answer(s) has/have been selected, thereby giving immediate feedback. The problem with standardization of the text became dominant when the project group reviewed the NoPlagiat Tutorial. We realized there were many different terms that could be used for the same thing and that the meaning of some terms could vary. Therefore we standardized the terms used in the tutorial and we also defined what certain key terms actually meant, e.g. Reference: Information about the source, author, publication year, title etc. 
Since we wanted to keep the size of the tutorial down, writing a short and in the same time an informative text was a great challenge.

The self-study tutorial was created in the web development tool Macromedia Dreamweaver 8 since this program was already used within the library organization and one member in the project group could already use the program. One drawback of this was that we only had one administrator with deep knowledge about the program. Later on one more project team member learned to edit the tutorial in the program.

In the literature we saw recommendations to use a student group to evaluate the designed tutorial [15]. Since such a group ideally should consist of students from different disciplines and study years, our first idea was to use the students that worked part time in the library since they had different backgrounds. This however did not work since we had no possibility to pay them for the extra time. We thought it was rather impractical and too time consuming to try to go out and recruit students for the test. Instead we decided that the NoPlagiat tutorial should be tested on several courses were we already teaching about academic conduct. Originally we wanted students to evaluate the NoPlagiat tutorial pilot in autumn 2013 before the launch of the NoPlagiat tutorial final version in spring 2014. However with the exception for a course in information retrieval given by the library with only six participants, these courses were only given during the spring semester, so we had to postpone the students' evaluation until later. This meant that we published the NoPlagiat tutorial final version first and evaluated it later. The drawback for us was that there were only room to make minor adjustments after the feedback from the students.

We did however make the NoPlagiat tutorial pilot available for our colleagues and staff members from the Disciplinary Board some weeks before the launch of the final version so they could evaluate it. One feedback was regarding the name of the self-study tutorial which until then had two names, one in Swedish and one in English, which was rather confusing for users which was an unfortunate oversight from the team's point of view. Therefore it was decided that NoPlagiat would be used as a unified name. The origin of the name sprung out of an idea to mix Swedish and English words to create a unique name that would be easy to remember. This exemplified the importance of having someone outside the project giving feedback, because they see errors and mistakes not obvious to the designers. The undergraduate students in the information retrieval course helped us with testing the time it took to complete the NoPlagiat tutorial. The test was carried out during their last lecture in the course, the fastest time was 8 minutes and the slowest time was 30 minutes, the rest were within the time spawn of 10-15 minutes, which was concluded to be within a reasonable amount of time.

We presented the NoPlagiat tutorial to our subject librarians in January 2014. The same day it was accessible from our public website. It had taken nearly 10 months to complete the NoPlagiat Tutorial and now it was time for the next step in the project. Promoting and evaluating it.

\section{PROMOTING AND EVALUATING THE NOPLAGIAT TUTORIAL}

The project team created a communication plan as an aid in promoting efforts and to get an overall view of the project, so that possible challenges could be identified, addressed and dealt with in good time. A communication plan is a tool for organizations to construct policy documents that will support the planning and implementing of communication e.g. a message to an intended target group [19]. The communication plan for the NoPlagiat tutorial included a background explaining the reason for the planned communication, a description of our communication needs, defining target groups, the results that the communication was intended to achieve and how to proceed to achieve them. It was created from an internal instruction document [20].

In our communication plan we identified two target groups, undergraduate students (including international students) and teachers. To reach them we needed to promote the NoPlagiat tutorial in different forums using different methods at the university during spring 2014. Students were believed to be the hardest to reach directly and to reach them we would need to rely heavily on subject librarians and teachers. We promoted the NoPlagiat tutorial under the library news column on the library's website and we posted information about it on our rolling TV and computer screens.

As a part of the communication plan our purpose was to incorporate NoPlagiat into an academic writing course for first-year undergraduate students. This would guarantee that the intended target group would use it [12]. So we contacted course coordinators for two suitable courses. The result of this communication was that NoPlagiat would be used in one of those courses. 
In February 2014 we presented the tutorial at a library board meeting. We also had the advantage of having the Deputy Vice-chancellor in the board who supported our project. This was a key meeting in our promotion since the board's members represented the four faculties (Arts and Sciences, Medicine and Health Sciences, Educational Sciences and Science \& Engineering/Institute of Technology) and the three student unions at the university. Our presentation of the tutorial was well received especially from the faculty members of Arts and Sciences and Science \& Engineering/Institute of Technology. The member from Science \& Engineering/Institute of Technology suggested making the NoPlagiat mandatory on a course taken by essentially all disciplines at his faculty, which was exactly what we wanted. The member from the Educational Sciences faculty appeared to be a bit more skeptical. Unfortunately the board member from the Medicine and Health Sciences and two of the student unions was not present at the meeting. These three persons were later informed about the tutorial. However our general conclusion was that the meeting had gone well.

With the recommendation from the library board we continued with the next step of our promotion campaign, which included contacting all the program committees and managers at the faculties by email in April 2014. In the letter we presented the NoPlagiat tutorial and recommended them to use it in courses in their education programs. A similar letter was constructed and distributed to the subject librarians who sent it to individual teachers in different educational programs. Even if there was a chance that the same letter would reach a teacher twice we wanted to make sure that it reached as many teachers as possible.

Three course where chosen for testing and evaluating the NoPlagiat tutorial in Mars and April 2014. They all belonged to the Science \& Engineering/Institute of Technology. Two of them where mandatory on two Master of Science in engineering programs. Two were given on the first study of year and the third on the third study of year. These courses were chosen since we already had an existing lecture about academic conduct so it was easy to include the NoPlagiat tutorial. We were aware of the dilemma that this limited the variety among the respondent's regarding number of disciplines and study of year.

Our idea of how to use the NoPlagiat tutorial was inspired by the teaching method flipped classroom. Instead of using the guide during class and taking up precious lecture time or only doing the NoPlagiat tutorial online without feedback, the students could do NoPlagiat on their own, for example before a session. Then during the lesson teachers and students could have a deeper discussion regarding the topics in the tutorial. We therefore sent an email to the students that were going to attend our lecture about academic conduct a few days before the session. The email contained information about the NoPlagiat tutorial and instructions to complete it before the session and to fill in an evaluation survey after the completion of the NoPlagiat tutorial. During the session we addressed and discussed the questions raised during the review of the NoPlagiat tutorial. This approach was successful since, rather than spending time on introducing the subject, the lecture could focus on questions from the students and concentrate on more in-depth explanations and examples. The evaluation survey gave us some feedback, some things were still considered unclear by the users after they had completed the tutorial. Three terms were mentioned: self-plagiarism, copyright and paraphrasing. So even though we had tried to be very clear in introducing the concept of paraphrasing it was still difficult for the users to fully understand it. We tried to make additional clarification of the three concepts, but we were not sure it would be enough. This doubt led to the creation of three exercises about citing, paraphrasing and copyright that could be used during the sessions after students had completed the NoPlagiat tutorial. There was some positive feedback. Some respondents commented that they learned more by doing the self-study tutorial than listening to a traditional lecture and that they liked that there was a quiz after every module which gave them a chance to rehearse what they had just read. Some negative feedback was that there was too much text in the tutorial and that the quiz had leading questions. A general frustration around how to cite properly in their written papers could also be read out from the respondent's answers. The students' complained about different rules between the courses and unclear citation rules.

As a result we tried to shorten the text and created more white space. Some also expressed the view that an introduction to plagiarism and copyright should be given earlier in their education, this opinion probably came from the undergraduate students taking on their third study of year. 
A follow-up survey was sent to the program committees and managers during April and May 2015 but had a very low response rate. Unfortunately from the responses we received, we learned that the program committees didn't think that the tutorial would fit in in their courses. I'm sorry to say that no respondent mentioned that NoPlagiat was used or discussed during a session. One program invited us to present the self-study tutorial on a department meeting which we did in September. On this meeting we encouraged the attending teachers to use the NoPlagiat tutorial, unfortunately we did not follow-up if this was done.

\section{UPDATING THE TUTORIAL}

The really first big update of the NoPlagiat Tutorial after the implementation was made during autumn 2015 and took several months to complete. The big challenge was for the members of the Plagiarism and Copyright issues group to find time to go through and update the tutorial since this was rather time consuming. Especially the English version had to wait before the update finally was finished. The larger update of the tutorial was mainly more unified examples of Harvard citations which was built upon the Guide to the Harvard system constructed by the university college of Borås. Some parts of the quiz were also modified and clarified. After comments from Swedish-speaking users we also included more citation examples in Swedish.

\section{CONCLUSIONS}

Our conclusion is that it is important to keep your expectations of the design of a self-study tutorial at a realistic level connected with the skills available to the project team. The lack of advanced programming skills in our project team made us out of convenience to choose a text-based self-tutorial. It did made it easier to develop and to update the tutorial and the project team concluded that the drawbacks of not using pictures or videos would be minor. Though this has not been thoroughly evaluated the feedback we have received from our users did not suggest that this was a major problem, we only had a few complains that there was too much text. One of the greatest challenges in the design that had not been anticipated was the problematic and time consuming task of standardizing the use of concepts and terms in the different modules of the tutorial. It is therefore recommended that early on and during the design of the tutorial to discuss and standardize the meaning and use of certain terms and concepts, ideally with the help of other colleagues, since the designers sometimes had a "blind-spot" to notice inconsistence use of terms.

We regret that we were not able to have a larger number of students to evaluate the NoPlagiat tutorial pilot before the publication of the final version, since there was limited possibilities to make major alternations in the tutorial after the publication. We did however not receive any suggestions for major changes in the NoPlagiat tutorial when the undergraduate students did evaluate it.

Overall the NoPlagiat tutorial got positive feedback from the user evaluation, several respondents saying they learned more from the tutorial than in a traditional lecture, which is a strong indicator of the usefulness of the tutorial. Still its usefulness needs to be evaluated more thoroughly before any major conclusions can be drawn. The use of a quiz after completing a module is something that some respondents thought was a positive experience since it was a possibility of repetition. We therefore feel that the inclusion of the quiz in the tutorial has been useful and can recommend it to others. The NoPlagiat tutorial's lack of any assessment quiz has been an ongoing discussion since the design of the tutorial. The project team wanted the tutorial to emphasize the learning about plagiarism and copyright for undergraduate students. A test might shift the focus from the learning process to just how to pass the test. The whole notion of the tutorial was built upon the idea that users would be taking the NoPlagiat tutorial with an interest of learning more about proper academic conduct. It might however be considered controversial since it was against the recommendation of the research studies consulted. Also several teachers have wished for a way to assess the students' results after completing the NoPlagiat tutorial and when informed that this is not possible some have decided not to use the tutorial in their courses. As to-date there are no plans to include an assessment quiz in the NoPlagiat tutorial, the discussion still continues and maybe it's something that will change in the future.

Explaining a complex subject like paraphrasing in a tutorial can be a bit of a challenge and it is advisable, if possible to add additional exercises and a discussion on a flipped classroom inspired session within a few days after that the tutorial has been completed by the users. Our own experience shows that this gives a good result in the students' learning process. 
We can confirm the conclusions in the literature reviewed that re-using already existing contacts with teachers is very crucial to get the opportunity to have the participants in an existing course evaluate the self-study tutorial. These relations were also of great importance for successfully promoting the selfstudy tutorial. It became evident the faculty (Science \& Engineering/Institute of Technology) where the project team had well established connections also is where we so far have seen the most success e.g. were able to incorporate the NoPlagiat tutorial into a course about academic writing for first-year undergraduate students.

It takes a lot of time and commitment to keep a tutorial up-to-date and even when a group has been appointed responsible for the maintenance it must be followed-up that the updates follows the predetermined schedule.

The inconsistence use of reference rules and lack of instructions on how these should be used seems to be a source of frustration among some undergraduate students. This was noticeable even in the design of the tutorial since we could not find one suitable set of reference style to use as an example. We instead had to define our own version of the Harvard style using the guide to the Harvard system from the university college of Borås as a reference. A more unified approach about reference rules among institutions and even disciplines are therefore desirable.

The project team must make sure that they continue to work towards the goals set up in the communication plan even after the publication of the tutorial. The limitation of time put into the project and the engagement of the group members in other working tasks makes it easy to fall back into ordinary routines and think that the tutorial will be implemented on its own. Parts of our communication plan concerning the follow-up of the initial promoting of the tutorial towards the program committees and managers was not implemented in a conclusive manner. The low response rate together with that the project team failed to remind respondents that had not answered made it harder to draw any real conclusions from the feedback we did get. So we both lack a holistic view of how the NoPlagiat tutorial is being used in courses on the faculties. Our conclusion is that it turned out to be harder to get the NoPlagiat tutorial incorporated in courses on the faculties than we had anticipated, even though the project had the expressive support of the Deputy Vice-chancellor. Our next step must be to make a more comprehensive follow-up of the use of the tutorial and how to proceed if it's not used in any wider extension which is indicated in our follow-up study.

The big risk right now is that the guide just will be forgotten and not used. We therefore need a tool to assess the positive effects of the NoPlagiat tutorial on a larger scale. An evaluation of the user statistics from the tutorial in how it's being used is also needed. A comprehensive follow-up on how the NoPlagiat is used on the faculties and promote the NoPlagiat tutorial more needs to be done, so it will be used on not only one but all four faculties at the university.

\section{ACKNOWLEDGEMENTS}

I would like to thank my Head of Department Christina Brage for her support and inspiration when writing this text. I also wish to thank my co-workers, without you there would be no NoPlagiat tutorial and no paper. 


\section{REFERENCES}

[1] P. Kyrk, "Disciplinärenden 2012 vid universitet och högskolor," Stockholm: Swedish Higher Education Authority, Rapport 2013:6, 2013.

[2] T. S. Dee and B. A. Jacob, "Rational Ignorance in Education A Field Experiment in Student Plagiarism," J. Hum. Resour., vol. 47, no. 2, pp. 397-434, 2012.

[3] C. H. S. Lin and L. Y. M. Wen, "Academic dishonesty in higher education-a nationwide study in Taiwan," High. Educ., vol. 54, no. 1, pp. 85-97, 2007.

[4] J. Walker, "Measuring plagiarism: researching what students do, not what they say they do," Stud. High. Educ., vol. 35, no. 1, pp. 41-59, 2010.

[5] A. Szabo and J. Underwood, "Cybercheats: Is information and communication technology fuelling academic dishonesty?," Act. Learn. High. Educ., vol. 5, no. 2, pp. 180-199, 2004.

[6] D. L. McCabe, "Cheating among college and university students : A North American perspective," Int. J. Educ. Integr., vol. 1, no. 1, pp. 10-11, 2005.

[7] C. Park, "In other (people's) words: Plagiarism by university students - literature and lessons," Assess. Eval. High. Educ., vol. 28, no. 5, pp. 471-488, 2003.

[8] R. Macdonald and J. Carroll, "Plagarism - a complex issue requiring a holistic institutional approach," Assess. Eval. High. Educ., vol. 31, no. 2, pp. 233-245, 2006.

[9] L. Emerson, "Plagiarism, a Turnitin Trial, and an Experience of Cultural Disorientation," in Originality, Imitation, and Plagiarism: Teaching Writing in the Digital Age, C. Eisner and M. Vicinus, Eds. Ann Arbor: University of Michigan Press, 2008, pp. 183-194.

[10] G. Pittam, J. Elander, J. Lusher, P. Fox, and N. Payne, "Student beliefs and attitudes about authorial identity in academic writing," Stud. High. Educ., vol. 34, no. 2, pp. 153-170, 2009.

[11] L. G. Power, "University Students' Perceptions of Plagiarism," J. Higher Educ., vol. 80, no. 6, pp. 643-662, 2009.

[12] K. K. Kellum, A. E. Mark, and D. A. Riley-Huff, "Development, assessment and use of an on-line plagiarism tutorial," Libr. Hi Tech, vol. 29, no. 4, pp. 641-654, Nov. 2011.

[13] P. A. Jackson, "Plagiarism Instruction Online: Assessing Undergraduate Students' Ability to Avoid Plagiarism," Coll. Res. Libr., vol. 67, no. 5, pp. 418-428, Sep. 2006.

[14] W. K. Mages and D. S. Garson, "Get the cite right: Design and evaluation of a high-quality online citation tutorial," Libr. Inf. Sci. Res., vol. 32, no. 2, pp. 138-146, Apr. 2010.

[15] H. Lund and N. O. Pors, "Web-tutorials in context: affordances and usability perspectives," Perform. Meas. Metrics, vol. 13, no. 3, pp. 197-211, 2012.

[16] "Stop Plagiarism," 2010. [Online]. Available: en.stopplagiat.nu/. [Accessed: 29-Jul-2016].

[17] "Refero - an Anti-plagiarism Tutorial," 2009. [Online]. Available: refero.Inu.se/english/aboutrefero/. [Accessed: 29-Jul-2016].

[18] Simon Fraser University, "Plagiarism Tutorial," 2016. [Online]. Available: www.lib.sfu.ca/help/academic-integrity/plagiarism-tutorial. [Accessed: 29-Jul-2016].

[19] Work Group for Community Health and Development the University of Kansas, "Community toolbox: Chapter 6. Communications to Promote Interest," 2016. [Online]. Available: ctb.ku.edu/en/table-of-contents/participation/promoting-interest/communication-plan/main. [Accessed: 29-Jul-2016].

[20] Linköping University Library, "Att skapa en kommunikationsplan”, 2015. 